\title{
Distribution System Power Losses Minimization using Network Reconfiguration
}

\author{
Muhammad Junaid Tahir ${ }^{1,2, *}$, Badri Abu Bakar', M. Alam³ ${ }^{3}$ M. S. Mazliham ${ }^{4}$ \\ ${ }^{1}$ Department of Engineering and Technology, Universiti Kuala Lumpur-BMI, \\ 8, Jalan Sungai Pusu, Gombak, 53100, MALAYSIA
}

${ }^{2}$ Department of Engineering and Technology, The University of Lahore,

1- Km Raiwind Road, Sultan Town, Lahore, 54590, PAKISTAN

${ }^{3}$ Department of Science and Technology, Ilma University

Korangi Road, Korangi Creek, Karachi, 75190, PAKISTAN

${ }^{4}$ Chancellory, Universiti Kuala Lumpur

1016, Jalan Sultan Ismail, Bandar Wawasan, Kuala Lumpur, 50250, MALAYSIA

*Corresponding Author

DOI: https://doi.org/10.30880/ijie.2018.10.07.001

Received 6 August 2018; Accepted 14 November 2018; Available online 30 November 2018

\begin{abstract}
This paper shows an efficacious approach for the perfect arrangement of a distribution system. To discover the switches best fusion, which outcomes a minimal power loss for the distribution radial configuration. To resolve the non-linear optimization problem here Modified Particle Swarm Optimization (MPSO) technique is projected for the minimization of system power losses. MPSO is an improved Binary Particle Swarm Optimization (BPSO) with modification of particle velocity in search space. To reveal the fitness of the anticipated approach relative investigation of MPSO with other preceding optimization techniques is done. To reconfigure a distribution network system, under base case loading conditions, IEEE 33 bus radial system is used. It is inspected that MPSO executes well as compare to GA, ACA and SPSO in respective of significance of power losses, which are improved and minimized up to $138.9275 \mathrm{~kW}$ and profile of voltage, which are enhanced and stabilized up to 0.94234 per unit in terms of minimum voltage in the system.
\end{abstract}

Keywords: Distribution Systems, Network Reconfiguration (NR), Binary Particle Swarm Optimization (BPSO), Modified Particle Swarm Optimization (MPSO)

\section{Introduction}

The growing distribution power system complexity has prolonged due to stressed surroundings in a radial system. Rapid development of industrial and residential heavy current load demands on distribution power system are primary fear for the engineers of planning by transitory of each particular day. Distribution power losses in Pakistan consuming massive volume nearby (17.4\%) [1]. Automation of distribution power system is a suitable way out for the decline of these losses, the positioning of the power devices having reactive adjustment, advance optimization methodologies and distribution arrangement by switching settlement is incorporated [2]. Distribution power system is a promising approach as compare to other well operational approaches because it increases the efficiency of the radial power system, stability and the power profile at the consumer's end. By changing the on/off position of tie switches (normally open) and 
partitioning switches (normally close) Distribution Network Reconfiguration (DNRC) may be explained through regulating the settled configuration of distribution power network [3-4]. Successive objectives can be achieved by DNRC:

$>$ Depletion of real power loss.

$>$ Depletion of bus current constraint violation.

$>$ Depletion of voltage of the branch constraint violation.

$>$ Depletion of unbalanced load feeder.

$>$ Depletion of amount of switching assignments.

$>$ Stability increment.

$>$ Supply consistency while fault occurrence.

The minimization of real power losses through network reconfiguration was early proposed by Merlin and Back [2]. To obtain the operational distributed tree construction of a radial power system with minimum real power losses the branch and bound technique was suggested. Insufficient constraints of the proposed approach were; huge operating time and emphasis only on real value of current for measurement of power in [2]. An innovative scheme for measuring variation in the real power loss caused by load fluctuating from one conductor to alternative conductor in the radial power system is suggested by Civanlar et al. [3]. Switching arrangement for the power loss minimization can be figure out smoothly by the radial system reconfiguration established on the primary form of the re arrange able switches. A heuristic scheme depends upon the load flow method to determine the minimal distribution power losses in a radial arrangement system proposed by Shirmohammadi and Hong [4]. This assessment technique is inefficient and the improved comprehensive outcome is not guaranteed are the constraints of the suggested technique [4]. Lot of scholars stated this issue while using this heuristic scheme. Applying genetic technique Rao et al. [5] implemented least distribution power losses through system configuration. Integer programing is adopted in [6] for solving the load symmetry and minimization of power losses problem. In [7] a heuristic technique is proposed by Gosami and Basu, for minimization of power flow throughout NR by opening of any one breaker with closing of other pair breaker to retain the network radial, the technique is suitable for the small power system and results in an enormous computational time for the massive power system.

Similarly using Simulated annealing [8-9] network reconfiguration for the power losses minimization problem estimated but the technique again has a calculation load as well massive computation time. K. Parsad et al in [10] has presented a fuzzy mutated genetic approach for the ideal arrangement of radial power system. To determine the issue regarding minimal power loss, various heuristic based techniques are proposed for example; skilled system [11], ant colony search [12], adaptive genetic algorithm [13], refined genetic algorithm [14] and selective particle swarm optimization [15] by arranging the radial power system. The techniques stated above for the massive networks can go up to large operational time which can be considered as a constraint for an online system. In this paper, Modified Particle Swarm Optimization (MPSO) technique is demonstrated for the reduction of real power losses in the radial network using NR. The presented technique performance is assessed on IEEE 33bus network, considering base load situations. The presented paper is divided into following parts: part 2 delivers, mathematical equations for operational issues. The proposed MPSO technique and flow of arithmetic problem are briefly explain in part 3. part 4 demonstrate the output of the evaluated IEEE distribution power system. The conclusion of this paper is described in part 5 .

\section{Problem Formulation}

To calculate the optimum radial effective arrangement that lessens the real power losses of the system by maintaining the essential functional constraints is thee basic target of DNRC issue. the real power losses minimization of a radial network $\left(\mathrm{P}_{\text {loss }}\right)$ is the key objective problem of DNRC, below its operating constraints, i-e, magnitude of system voltage, maximum rated load on a feeder and network radial arrangement. Minimal real power losses which is the basic element can be expressed as:

$$
\operatorname{MinimizeF}=\operatorname{Minimize}\left(P_{\text {loss }}\right)
$$

Subjected to:

$$
\begin{aligned}
& V_{i_{\min }} \leq V_{i} \leq V_{i_{\max }} i=1,2,3, \ldots \ldots . . N_{b} \\
& I_{i} \leq I_{i_{\max }} i=1,2,3, \ldots \ldots . .\left(N_{b r}+N_{t s}\right) \\
& \operatorname{Det}(A)=1 \text { or }-1(\text { radial..system })
\end{aligned}
$$




$$
\operatorname{Det}(A)=0(\text { Non }- \text { radial..system })
$$

Where, $\left(\mathrm{P}_{\text {loss }}\right)$ is the total real power loss of the network; $\mathrm{V}_{\mathrm{i}}$ is the bus i voltage level; $\mathrm{V}_{\max }, \mathrm{V}_{\min }$ are the upper and lower voltage node limitations $\left(\mathrm{V}_{\min }=0.9 \mathrm{p}\right.$. u. $a n d \mathrm{~V}_{\max }=1.0 \mathrm{p}$. u. $)$ respectively; $\mathrm{I}_{\text {imax }}, \mathrm{I}_{\mathrm{i}}$ is the $\mathrm{i}^{\text {th }}$ branch upper current limitation and current level; Node incidence matrix is A respectively;

A single line diagram of the distribution power system is displayed in Fig.1. And the mathematical equation for the power flow of the system can be stated as [16]:

$$
\begin{aligned}
& P_{i+1}=P_{i}-P_{L i+1}-R_{i, i+1} \frac{\left(P_{i}^{2}+Q_{i}^{2}\right)}{\left|V_{i}^{2}\right|} \\
& Q_{i+1}=Q_{i}-Q_{L i+1}-L_{i, i+1} \frac{\left(P_{i}^{2}+Q_{i}^{2}\right)}{\left|V_{i}^{2}\right|}
\end{aligned}
$$

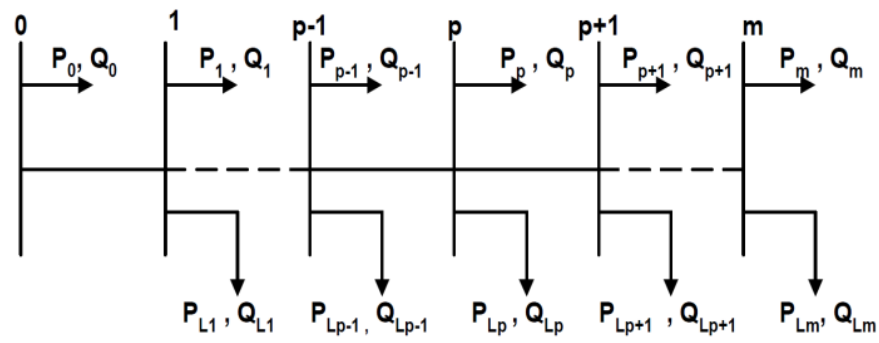

Fig. 1 - Single Line Diagram of Main Feeder.

$$
\left|V_{i+1}\right|^{2}=\left|V_{i}\right|^{2}-2 R_{i, i+1} P_{i}+X_{i, i+1} Q_{i}+\left(R_{i, i+1}^{2}+X_{i, i+1}^{2}\right) \frac{\left(P_{i}^{2}+Q_{i}^{2}\right)}{\left|V_{i}^{2}\right|}
$$

$P_{i}$, line active power which is passing out of bus i.

$Q_{i}$, line compensative power which is flowing out of bus i.

$P_{L i}$, load active power which is at bus $\mathrm{i}$.

$Q_{L i}$, load compensative power which is at bus $\mathrm{i}$.

$R_{i, i+1}$, line resistance which is among the bus $\mathrm{i}$ and $\mathrm{i}+1$.

$X_{i, i+1}$, line reactance which is among the bus $i$ and $i+1$.

Among the buses $i$ and $i+1$ the active power losses is calculated as:

$$
P_{L, L o s s(i, i+1)}=R_{i, i+1} \frac{\left(P_{i}^{2}+Q_{i}^{2}\right)}{\left|V_{i}^{2}\right|}
$$

The feeder over all real power losses are calculated as:

$$
P_{L o s s}=\sum_{i=1}^{k} P_{L, L o s s(i, i+1)}
$$

where $P_{\text {loss }}$ is the system over all power loss, that is attained by summing up all the line losses of power for all feeder segments. 


\section{Modified Particle Swarm Optimization}

Particle swarm optimization (PSO) was firstly introduce by Eberhart and Kennedy in 1995 [17]. To understand the nature behaviour, this technique has self-learning population inspiration which is taken from birds movement in a joint swarm, a group of bees or a fishes flock.

Numerous types of PSO in last twenty years are suggested for the improvement of the result quality, merging velocity and its consistency improvement. Eberhart and Kennedy [18] suggested the PSO discrete version by fluctuating the search space into binary. The anticipated Modified PSO is also another altered form of binary PSO, in which alteration in particle velocity in search space is done which narrowed the particle search towards better quality solution. mathematical arrangement is presented in this segment, for the proposed technique.

Velocity and position vectors, in a D dimensional search space for the $i^{\text {th }}$ particle, perhaps derived as:

$$
V_{i}=\left(v_{i 1}, v_{i 2}, \ldots \ldots . . . v_{i D}\right), X_{i}=\left(x_{i 1}, x_{i 2}, \ldots \ldots . . . x_{i D}\right)
$$

In the same way, the particle best initial position is determined and expressed as:

$$
P_{b e s t i}=\left(p_{i 1}, p_{i 2}, \ldots \ldots . . . p_{i D}\right)
$$

From entire particles in the group if till now $g^{\text {th }}$ particle is the best, it is epitomized as:

$$
g_{\text {besti }}=p_{\text {bestg }}\left(p_{g 1}, p_{g 2}, \ldots \ldots . . . . p_{g D}\right) \text {. }
$$

The velocity of particle and its position both are simplified as:

$$
\begin{gathered}
v_{i D}^{k+1}=(1-w) * w * v_{i D}^{k+1}+w^{*} v_{i D}^{k}+c_{1} * r_{1}\left(P_{b e s t i D}^{k}-x_{i D}^{k}\right)+c_{2} * r_{2}\left(g_{\text {bestiD }}^{k}-x_{i D}^{k}\right) \\
x_{i D}^{k+1}=x_{i D}^{k}+v_{i D}^{k+1}
\end{gathered}
$$

Where $i=1,2,3 \ldots \ldots \ldots \ldots . m$; the weight of inertia is $w$; the constants of acceleration are $c 1$ and $c 2$; the random values are $r 1$ and $r 2$ ranges between [0,1]; Function of Weight can be calculated as:

$$
w=w_{\max }-\frac{w_{\max }-w_{\min }}{\text { iter }_{\max }} * \text { iter }
$$

$w_{\max }, w_{\min }$ are the opening value of weight and the closing value of weight, respectively; $i t e r_{\max }$ are the maximum iterations number; iter is the current number of iteration;

To restrict the velocities with in the limit of $[0,1]$ the sigmoid conversion is used in binary PSO for the velocity elements and constraint the particles placements to be either 0 or 1 .

$$
\begin{aligned}
& \operatorname{sig}\left(v_{i D}^{k+1}\right)=\frac{1}{1+\exp \left(-v_{i D}^{k+1}\right)} \\
& x_{i D}^{k+1}=\left\{\begin{array}{l}
1, \text { if } \sigma<\operatorname{sig}\left(v_{i D}^{k+1}\right) \\
0, \text { if } \sigma \geq \operatorname{sig}\left(v_{i D}^{k+1}\right)
\end{array}\right\}
\end{aligned}
$$

Abdelaziz et al proposed, an ordinary modification to binary PSO [15] by modifying iteration number and size of population in the search space. Particles velocities are limited to around maximum and minimum values $\left[v_{\max }, v_{\min }\right]$ using (16).

$$
v_{i D}^{k+1}=\left\{\begin{array}{l}
v_{\max } \text { if }, v_{i D}^{k+1}>v_{\max } \\
v_{i D}^{k+1} \text { if },\left|v_{i D}^{k+1}\right| \leq v_{\max } \\
v_{\min } \text { if }, v_{i D}^{k+1} \leq v_{\min }
\end{array}\right\}
$$




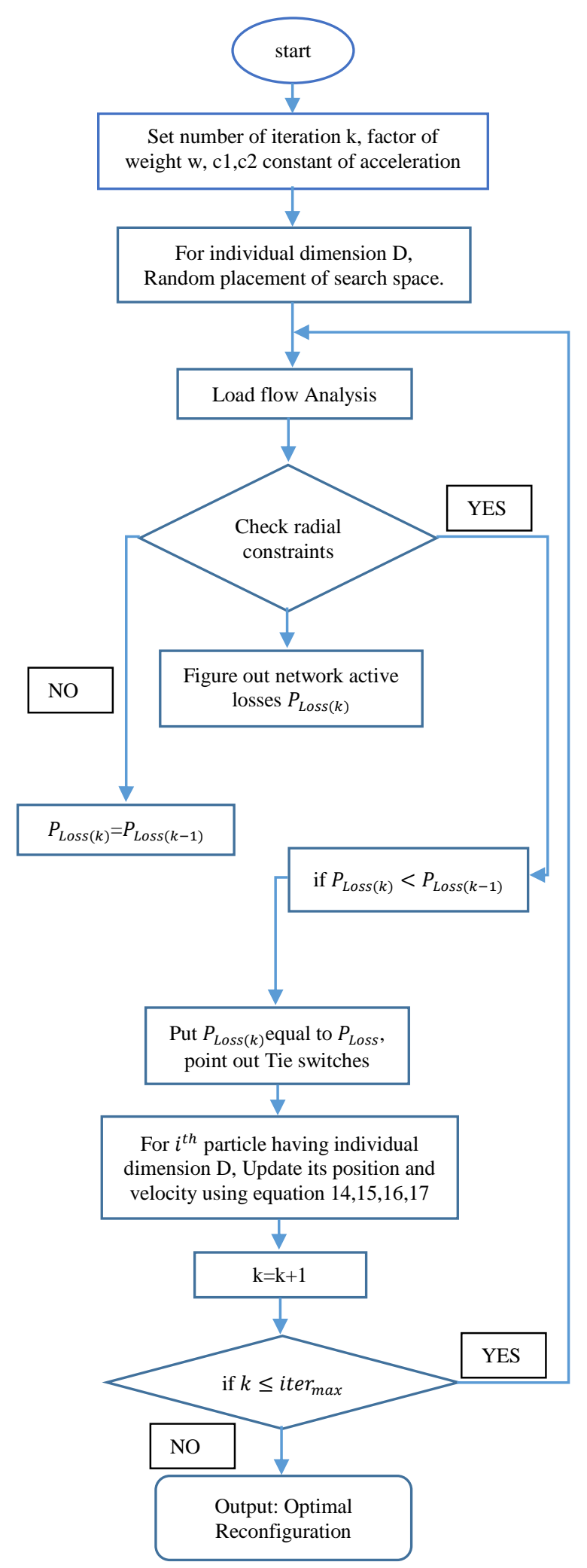

Fig. 2 - Flowchart of MPSO method. 
To limit the value of $i^{\text {th }}$ velocity of particle for dimension D between the range of maximum and minimum (17) is used.

$$
v_{i D}^{k+1}=\left\{\begin{array}{l}
\operatorname{rand}^{*} v_{i D}^{k+1} \text { if },\left|v_{i D}^{k+1}\right|=\left|v_{i D}^{k}\right| \\
v_{i D}^{k+1}, \text { otherwise }
\end{array}\right\}
$$

The sequence is given of the method proposed in Fig. 2. The three key phases to resolve DNRC issue by MPSO are: 1. To frame the set of dimensions.

2. To spot in respective dimensions of the search space.

3. Using MPSO locate best solution from the search space.

On locking all the tie switches the set of dimensions in a radial network are equivalent to set of loops created. A certain dimension in the search space consists of the loop branches, denoted by this dimension. In any search space the network branches which do not exist in any mesh are not included and therefore also not accounted in the optimization technique. The common branches for the loops and dimensions, at a time must include only in one dimension that can be run randomly. The MPSO can be functional to get the optimal result, at the instant the dimensions and the individual dimension of search space is stated.

\section{Using the Template}

References IEEE 33-bus radial network is used to test the presented technique. To compute the effectiveness of the suggested technique under base loading conditions, comparative analysis of MPSO with GA and ACA for NR, is conceded. To test the proposed technique MATLAB 2015 is used, and the simulations are done on a computer with Intel(R)Core(TM)i5-6500, 3.20GHz, 8 GB RAM.

IEEE 33 bus system single line diagram is shown in Fig.3. The radial network has 5 normally open tie switches and 32 normally closed sectionalizing switches. The 5 tie switches are 33,34,35,36,37 particularly. The tie switches are indicated by dotted lines and the solid lines represents the sectionalizing switches in Fig. 3.

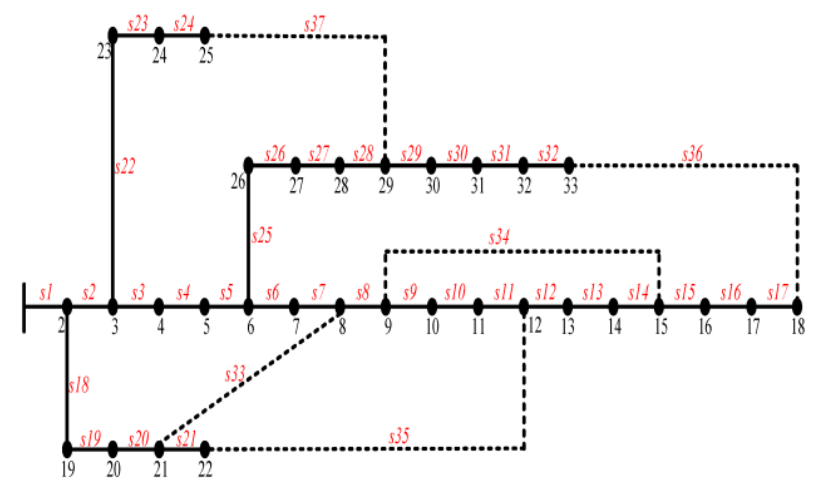

Fig. 3 - Single Line Diagram of IEEE-33 Bus System

Before reconfiguration, the active power losses are $208.46 \mathrm{~kW}$ and at bus 18 least voltage is 0.91075 p.u. As Fig. 3 shows, when five tie switches are closed; as the result five loops are developed. consequently, the dimension numbers of this network, 33 bus are five. Table I shows the particular loops along with dimensions and the search space for particular dimension. While sorting the optimal solution by MPSO the "S1" switch not included in any loop and hence it is not accounted. As specified in the flow chart Fig .3, the common switches of two dimension are included randomly in one dimension. Later explaining the search space and identifying the dimensions, (MPSO) technique is presented to perceive the radial optimal reconfiguration for the base loading case conditions.

Table 1 - Loops of 33 bus system

\begin{tabular}{|c|c|c|}
\hline Loops & Dimension & Switches \\
\hline 1 & $S_{d 1}$ & $8,9,10,11,21,33,35$ \\
\hline 2 & $S_{d 2}$ & $2,3,4,5,6,7,18,19,20$ \\
\hline 3 & $S_{d 3}$ & $12,13,14,34$ \\
\hline 4 & $S_{d 4}$ & $15,16,17,29,30,31,36,32$ \\
\hline 5 & $S_{d 5}$ & $22,23,24,25,26,27,28,37$ \\
\hline
\end{tabular}


To estimate the efficiency of the suggested strategy, the radial optimal reconfiguration under base loading circumstances is also gathered using MPSO. Parameters used in power distribution system simulation for MPSO are given in Table 2 .

Table 2 - Parameters of MPSO

\begin{tabular}{|c|c|}
\hline Parameters & MPSO \\
\hline Maximum weight & 0.9 \\
\hline Minimum weight & 0.4 \\
\hline iter $_{\max }$ & 60 \\
\hline $\mathrm{C} 1, \mathrm{C} 2$ & 2.0 \\
\hline
\end{tabular}

\subsection{Distribution Losses}

Table. 3 shows that the minimization in active power loss is more noticeable in base loading when the NR is achieved by using MPSO technique. Before optimal switching configuration the power losses are $208.46 \mathrm{~kW}$ for the base case which is minimized up to $33.36 \%$ after switching configuration is done with MPSO as contrast to $31.0 \%$ [15] where SPSO technique is employed, 30.15\% [19] where GA technique is used and 33.08\% [20] where ACA technique is applied. It can be seen in the table 3 that ACA, SPSO and proposed method gets the best optimal configuration for minimal losses in the system is 7,9,14,32,37. Hence it can be decided that MPSO outperformed SPSO and GA and ACA for reduction of the active power losses.

Table 3 - Comparison of MPSO with other techniques

\begin{tabular}{|l|c|l|l|c|c|}
\hline \multirow{2}{*}{ Item } & Initial Configuration & \multicolumn{2}{|l|}{ Final Configuration } \\
\cline { 3 - 6 } & & GA [19] & ACA [20] & SPSO [15] & Proposed Method \\
\hline Tie Switches & $33,34,35,36,37$ & $9,28,33,34,36$ & $7,9,14,32,37$ & $7,9,14,32,37$ & $7,9,14,32,37$ \\
\hline Power Loss(KW) & 208.459 & 141.6 & 139.55 & 143.8 & 138.9275 \\
\hline Loss Reduction (\%) & ----- & 30.15 & 33.08 & 31.00 & 33.355 \\
\hline Minimum Voltage p.u & 0.91075 & 0.9310 & 0.9375 & 0.936 & 0.94234 \\
\hline
\end{tabular}

Table 4 - Statistical Analysis after 50 run

\begin{tabular}{|l|l|l|l|}
\hline Best Ploss & Worst Ploss & Average Ploss & Stand Deviation \\
\hline 138.9275 & 150.8868 & 139.7563 & 2.0882 \\
\hline Best Voltage & Worst Voltage & Average Voltage & Stand Deviation \\
\hline 0.9423 & 0.9360 & 0.9421 & 0.0011 \\
\hline
\end{tabular}

It can be seen through Fig.4 that initially before reconfiguration, power losses at each branch of the network have high magnitude of impulses specially line two and five and seven it can be seen through Fig. 4 that these losses are noticeably minimized after network reconfiguration using MPSO technique for the base loading condition. It can be observed that there is slight change in power losses from bus 20 to bus 37 it is due to optimal reconfiguration of switches.

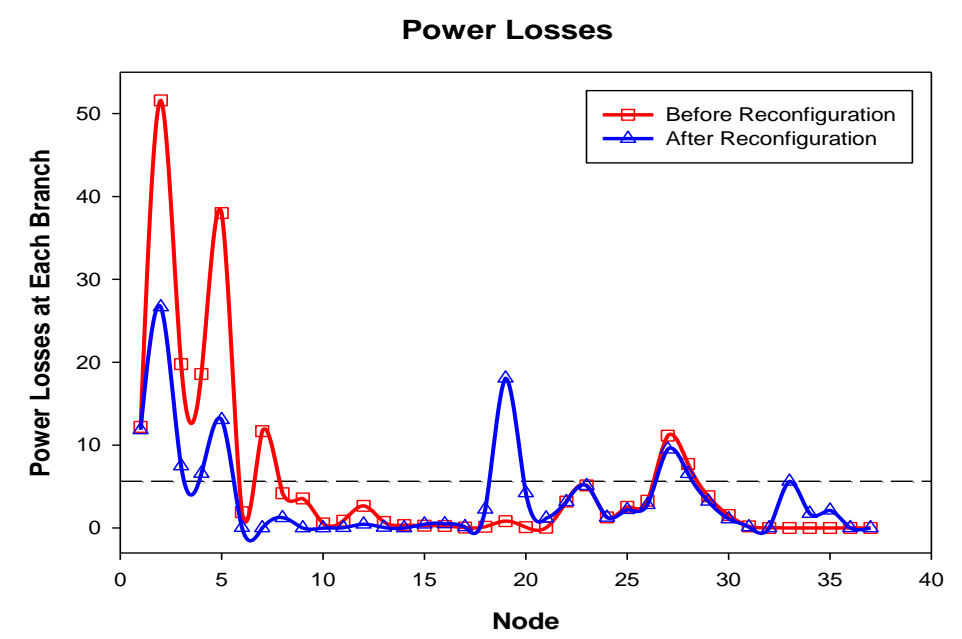

Fig. 4 - Impact of switching configuration on power losses using MPSO. 
Using optimal reconfiguration power flow in some branches are reduced and in some branches power flow is enhanced. Due to which power losses are slightly changed in bus 20 to bus 37. branches in some Load on buses are shifted to other buses which have greater voltage.

\subsection{Voltage Profile of the Network}

Profile of voltage is enhanced by switching configuration executed as a result of presented techniques; when NR is done by MPSO algorithm yet noteworthy raise is witnessed for base loading conditions. In Fig. 5 the influence of switching configuration on voltage altitudes using MPSO is displayed graphically. After reconfiguration, the least voltage of the bus is enhanced to 0.94234 per unit. at bus 32 using MPSO algorithm for base case. It can be seen in Fig. 5 that voltage gets reduced from bus 21 to 25 . It is happened due to optimal reconfiguration of switches, which shift some load where buses have voltage near to 1 per unit so that other system bus voltages can be increase.

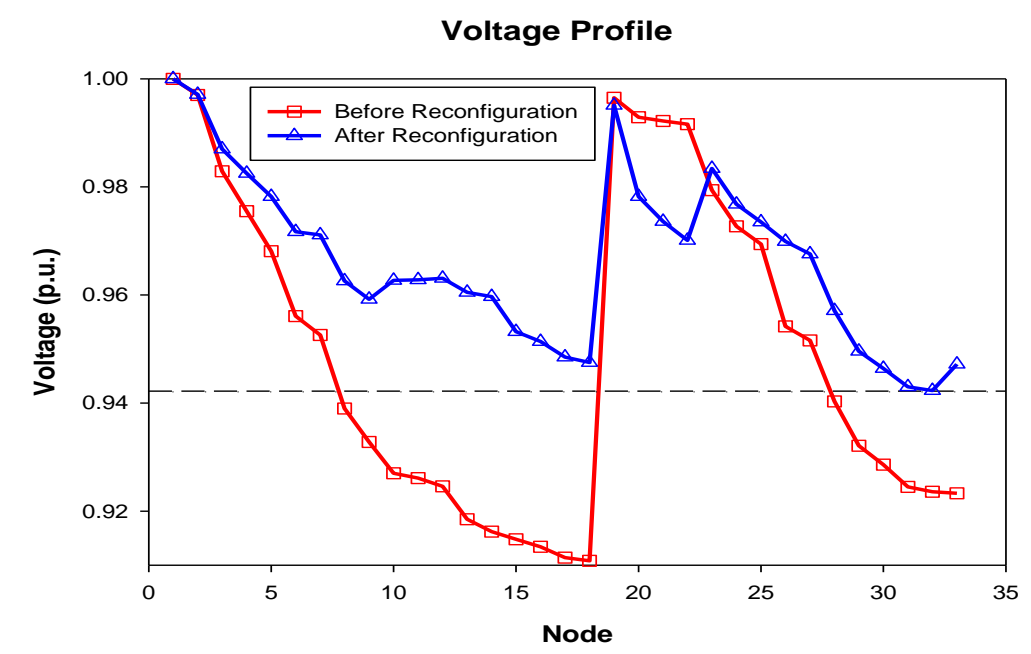

Fig. 5 - Impact of switching configuration on voltage altitude using MPSO.

\subsection{Voltage Angle of the Network}

It can be seen through Fig.6 that by using MPSO technique for base loading condition before network reconfiguration, voltage angle of each node of the network have higher degree of phase shift which is being prominently controlled and minimized after reconfiguration of the network by applying suggested technique on the system. As MPSO is improving the voltage profile and minimum voltage in the system is enhanced up to 0.94234 per unit. Similarly, voltage angle is phasor value of the enhanced voltage it is also improved.

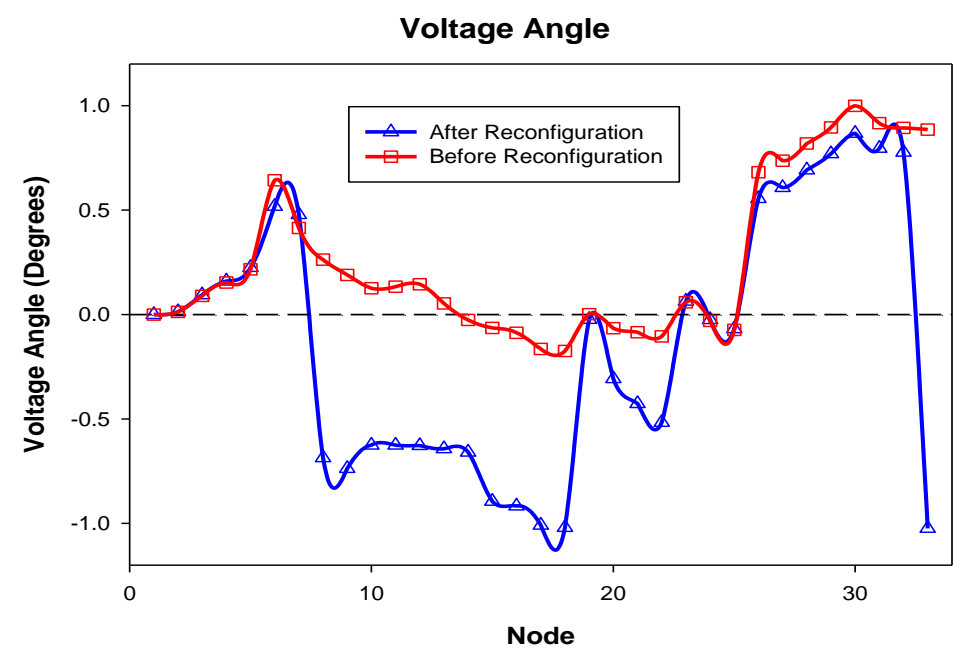

Fig. 6 - Impact of switching configuration on voltage angle using MPSO. 


\section{Conclusion}

MPSO is effectively implemented in this paper, for IEEE 33 bus system beneath base loading conditions, to optimize power distribution radial system for least active power losses and enhanced profile of voltage. Results obtained from simulation are compared with GA, ACA and SPSO algorithm. It can be concluded from the results that MPSO outclassed the other compared algorithms with noteworthy minimization of losses and voltage profile improvement in a radial distribution network. Further this proposed technique can be tested for the power losses minimization of large radial distribution system. More over MPSO technique can also be tested for the other conventional methods to minimize power losses of the system i-e, Capacitor placement and Generator placement.

\section{References}

[1] "Electric power transmission and distribution losses (\% of output)," World Bank, [Online]. Available: http://data. worldbank.org/indicator/EG.ELC.LOSS.ZS?end=2014\&locations=PK\&name_desc=false \&start=1971 \&view=chart. [Accessed 21 March 2018].

[2] RS Rao, K Ravindra, K. Satish, and S. V. L. Narasimham. (2013). "Power loss minimization in distribution system using network reconfiguration in the presence of distributed generation." IEEE transactions on power systems 28, Vol no. 1, pp: 317-325.

[3] S.Rao, S. V. L. Narasimham, M. R. Raju, \& A. S. Rao, (2011). Optimal network reconfiguration of large-scale distribution system using harmony search algorithm. IEEE Transactions on power systems, 26 vol.3, pp:1080-1088.

[4] M. Lavorato, J. F. Franco, M. J. Rider, \& R. Romero, (2012). Imposing radiality constraints in distribution system optimization problems. IEEE Transactions on Power Systems, 27, Vol.1, pp:172-180.

[5] Rao, R. Srinivasa, Kumudhini Ravindra, K. Satish, and S. V. L. Narasimham. (2013). "Power loss minimization in distribution system using network reconfiguration in the presence of distributed generation." IEEE transactions on power systems 28, Vol.1, pp. 317-325.

[6] Jabr, Rabih A., Ravindra Singh, and Bikash C. Pal. (2012). "Minimum loss network reconfiguration using mixedinteger convex programming." IEEE Transactions on Power systems 27, vol. 2, pp. 1106-1115, May.

[7] S. K. Goswami and S. K. Basu, (1992). "A new algorithm for the reconfiguration of distribution feeders for loss minimization,” IEEE Trans. Power Del.7, vol. 3, pp. 1484-1491.

[8] Franco, John F., Marcos J. Rider, Marina Lavorato, and Rubén Romero. (2013). "A mixed-integer LP model for the reconfiguration of radial electric distribution systems considering distributed generation." Electric Power Systems Research 97, pp. 51-60.

[9] Ferreira, Rafael S., Carmen Lucia Tancredo Borges, and Mario VF Pereira. (2014). "A flexible mixed-integer linear programming approach to the AC optimal power flow in distribution systems." IEEE Transactions on Power Systems29, vol. 5, pp. 2447-2459.

[10] K. Prasad, R. Ranjan, N. C. Sahoo, and A. Chaturvedi, (2005). "Optimal configuration of radial distribution systems using a fuzzy mutated genetic algorithm,” IEEE Trans. Power Del.20, vol. 2, pp. 1211-1213.

[11] J. M. Solanki, S. Khushalani, \& N. N. Schulz, (2007). A multi-agent solution to distribution systems restoration. IEEE Transactions on Power systems, 22 Vol.3 , pp:1026-1034.

[12] Wu Yaun-Kang, Lee Ching-Yin, Liu Le Chang, and Tsai Shao-Hong, (2010). "Study of reconfiguration for the distribution system with distributed generators," IEEE Trans. Power De. 25,vol. 3,pp. 1678-1685.

[13] A. Swarnkar, N. Gupta, and K. R. Niazi, (2010) "Minimal loss configuration for large scale distribution system using adaptive genetic algorithm," 16th National Power System Conference, pp.647-652.

[14] Z. Zhu, (2002) "Optimal reconfiguration of electrical distributed network using redefined genetic algorithm," Electr. Power Syst. Res.62, vol. 1, pp. 37-42.

[15] Khalil, T. M. Khalil and A. V. Gorpinich, (2012).”Reconfiguration for loss reduction in distribution system using selective particle swarm optimization," Int. J. of Multidisciplinary sciences and Eng, vol. 3, vol. 6, pp,1-4.

[16] S. Ghosh and K. S. Sherpa, (2008), “An efficient method for load flow solution of radial distribution networks," Int J. Elect. Power Energy Syst. Eng, vol.1, vol. 2, pp. 108-115.

[17] J. Kennedy and R. Ebehart, (1995), "Particle swarm optimization,” Proc. IEEE Int. Conf. on Neural Networks, vol. 4, pp. 1942-1948.

[18] J. Kennedy and R. Ebehart, (1997), “A discrete binary version of the particle swarm algorithm,” IEEE Int. Conf. on Systems, Man, and Cybernetics (SMC 97), vol. 5, pp. 4140-4109.

[19] Srinivasa Rao Rayapudi, Venkata Lakshmi, Narasimham Sadhu, Ramalinga Raju Manyala, Srinivasa Rao A. (2011)." Optimal network reconfiguration of large-scale distribution system using harmony search algorithm". IEEE Trans Power Syst 26, vol. 3, pp.1080-1088.

[20] Kasaei, M. J., and M. Gandomkar. (2009)."Loss reduction in distribution system with simultaneous using of capacitor placement and reconfiguration by ant colony algorithm." International Conference On Power System. 